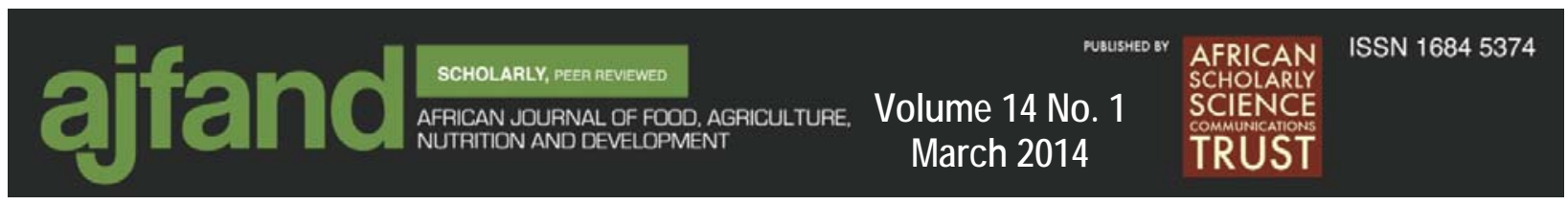

\title{
III HEALTH AND AGRICULTURAL PRODUCTION: \\ EVIDENCE FROM KOGI STATE OF NIGERIA
}

\section{Onuche $\mathrm{U}^{1}$, Opaluwa HI ${ }^{1}$ and MH Edoka ${ }^{1}$}

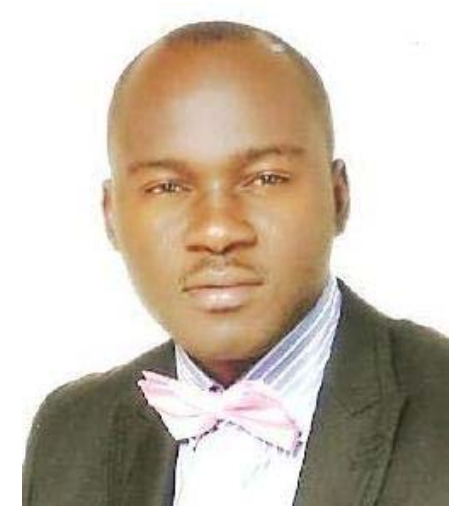

Onuche Unekwu

*Corresponding author's e-mail: kanstarr@yahoo.com

${ }^{1}$ Department of Agricultural Economics and Extension, Kogi State University, Anyigba, Nigeria 


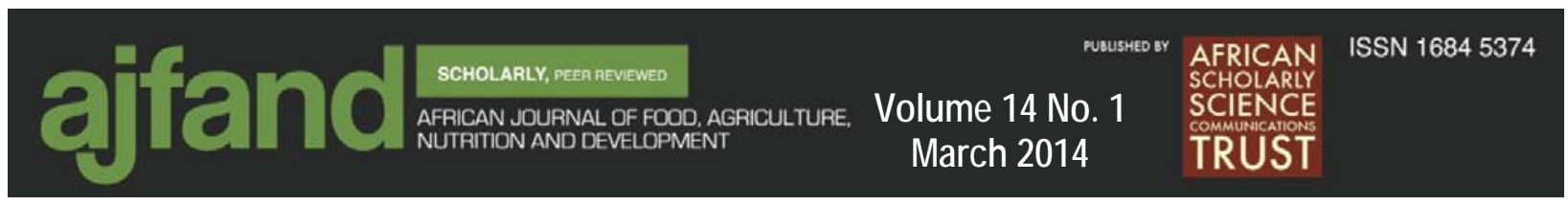

\begin{abstract}
This study was carried out to analyse the impact of ill health on agricultural outputs in rural areas of Kogi state, central Nigeria. The motivation derives from the fact that rural areas which are strategically important for national food security are more prone to health hazards as a result of the poor nature of health services arising partly from neglect by government. The objectives were to present the socioeconomic characteristics of the rural farm households and identify the prevailing health and agricultural production nexus in the area. The use of multistage random sampling procedure was employed in the selection of 263 rural households for questionnaire administration in order to elicit relevant data related to their farming enterprises and health. The use of descriptive statistics and production function analysis were employed. The study revealed that the average age of the household heads was 46.4 years while the average household size was 6.5 persons. Also, the average farm size was 1.43 ha and the average number of years of formal education was found to be 7.4. Furthermore, the study revealed that the most prominent disease conditions affecting farm families were malaria fever, typhoid fever and diarrhea and these led to an average of 8.2 days reduction in time available for farm work in a farming season. Result from the production function analysis revealed that the elasticities of farm size (0.419), family size (0.099), number of contacts with extension staff (0.018), labour (0.012) and naira amount of credit accessed (0.25) were positively signed and significant at 1\%, 10\%, 1\%, 5\% and 1\% respectively; while number of days of farm work lost to ill health was negatively signed (0.09 ) and significant at $5 \%$. Findings suggest that focusing on number of days of farming activities lost to ill health in a household might help elicit a clearer picture of the effect of transient ill health on agricultural production. More research and development effort in the provision of and accessibility to health care in the rural areas in order to reduce the incidence of diseases are recommended. Such efforts should also include the provision of adequate health and environmental education for the rural population as the most common ailments discovered in the study area are actually hygiene and environment related.
\end{abstract}

Key words: Health, labour, rural, farm, output 


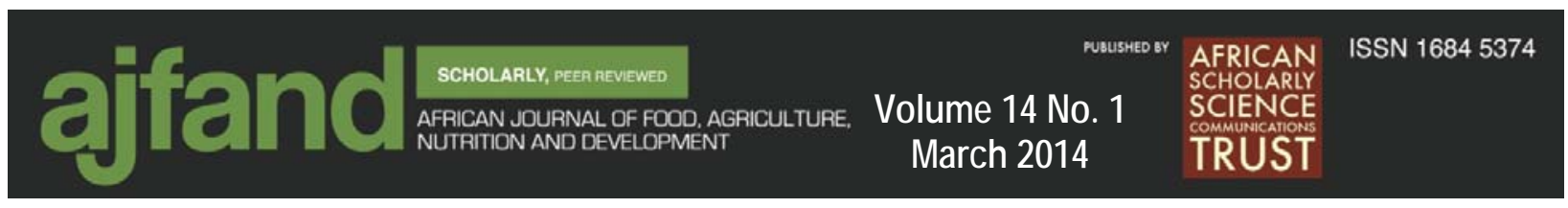

\section{INTRODUCTION}

Rural areas have continued to receive attention from successive governments in Nigeria owing to their strategic importance as the agricultural base of the nation. About $90 \%$ of the Nigerian food supplies come from small holder farmers (farmers with less than three hectares of land), and most industries are agro based. It has also been noted that about $40 \%$ of the country's GDP comes from the agricultural sector which also accounts for $70 \%$ of non-oil export Olayemi [1]. The agricultural products that account for the above are mostly sourced from the rural areas [2, 3, 4]. However, these areas are prone to a lot of infrastructural and welfare problems. One of these problems is their susceptibility to health hazards. Rural communities are often more prone to health problems such as malaria, guinea worm infection, HIV/AIDS [1].

Both as a direct indicator of welfare and a factor that impacts productivity, health status is important because health is a major form of human capital [5]. There exists substantial agreement in literature on the relationship between health and economic development, as health is related to capability $[6,7,8]$. Health problems, apart from negatively affecting the state of welfare of affected households, affects agriculture and economic development negatively through the reduction of available labour hours for economic activities, premature loss of young human resources and high cost of disease treatment which adds to the economic burden of poor rural households [1].

There is consensus among development economists that health is an important variable in national development. It has been revealed by Gallup and Sachs [9] that countries with severe incidence of malaria had only $33 \%$ of the income levels of countries that were malaria free in 1995 and grew 1.3\% slower per year over the period of 1965-1995. Estimates by McCarthy, Wolf and $\mathrm{Wu}[10]$ also indicate that malaria reduces economic growth by $0.55 \%$.

Research focusing on agriculture has revealed the negative impact of ill health especially on the welfare of agricultural households- which ultimately affect overall economic development. For instance, Asenso-Okyere, Chiang, Thangata and Andam [11] reported that the effects of ill health on farm households include three broad impacts: absenteeism from work due to morbidity (and eventual death); diversion of family time to caring for the sick; and the loss of savings and assets in the course of dealing with diseases and its consequences. They reported further that the long-term impacts of ill health include loss of farming knowledge, reduction of land under cultivation, planting of less labor-intensive crops, reduction of variety of crops planted, and reduction of livestock. The ultimate impact of ill health according to their report is a decline in household income and food insecuritythat is, a severe deterioration in household livelihood. In a study of 21,000 households in Ghana, it was found that almost half of the households registered losses of family income, one third of them experienced a decline in food production and $41 \%$ experienced decline in food consumption due to ill health [12]. 


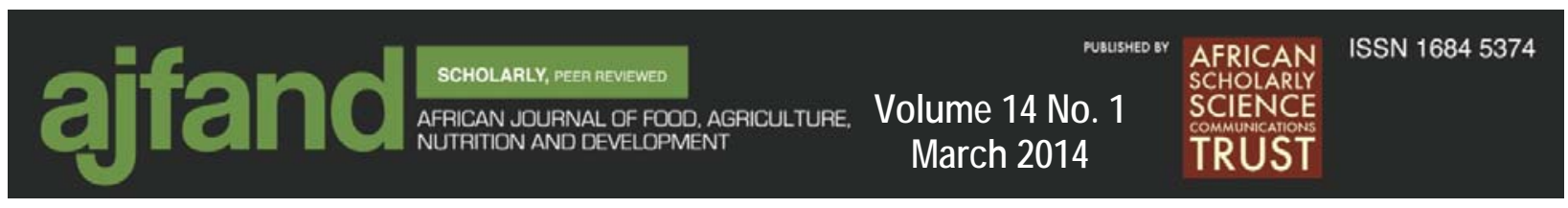

Although some studies like Mock, Gloyd, Adjei, Acheampong and Gish [12] dwelt on the general impacts of ill health on agricultural households, the impact of ill health as it relates to agricultural production was only implied, not directly estimated. Studies that have measured the direct effect of ill health on agricultural production have mostly dwelt on the impact of one or two selected diseases on a single crop, and relied on incidence of the disease in an area without taking into cognizance the hours or days of agricultural activities lost due to health problems; see Audibert [13] and Audiber and Etard [14] for instance. Where hours/day of labour loss was used as an explanatory variable in the production function as in Larochelle and Dalton [15] the effect was divided into direct and indirect dimensions: where the direct impact relates to a situation in which the sick person was directly involved with agricultural production while the indirect dimension relates to a situation where the sick member of a household was not involved with farm work. It is certain that even the illness of those not directly involved with farm work could lead to loss of farm work hours where such an individual has to be catered for by a member involved with farm work. In such a case, the impact of ill health on production can still be direct.

The study was undertaken to assess the overall impact of health shock on agricultural production. In doing this, the number of days lost to ill health resulting from the prevalent transient (non terminal, temporal) disease conditions in the last farming season (a farming seasons starts at the commencement of the rains in April and lasts till October) was considered. This is in addition to the fact that there is paucity of empirical evidence on the health - production relationship in the study area. The study area is largely agrarian and highly vulnerable to health hazards as a result of poor commitment to primary health care delivery by local governments [16]. The study area is the second poorest state in the federation [17].

The poverty line for rural agricultural producers in the country is $\$ 834.02$ per month $(1 \mathrm{USD}=137$ Naira); this was estimated by the National Bureau of Statistics NBS [17], the statutory body saddled with the responsibility of data collection, processing and analysis, in the 1996/1997 national consumer survey using the 1999 prices. An independent study by Omonona [18] found the poverty line for agricultural producers in Kogi state to be $\$ 814.21$. Based on the poverty line of 1 USD per day, about $78 \%$ of Kogi people are poor. Decades of marginalization from mainstream national politics and resources (the indigenes are minority tribes some of which are Igala, Ebira and Bassa) as well as the subsistence and rudimentary nature of agriculture- which is its dominant industry- may be plausible reasons for the ordeal of Kogi state.

To meet the objective of this study, the following research questions were raised: What are the socioeconomic characteristics of farmers? What are the major ill health conditions prevalent in the area? What numbers of days of agricultural activities were lost due to ill health during the last farming session? And, what effect do these health problems have on agricultural production? The specific objectives included to: (a) present the socioeconomic 


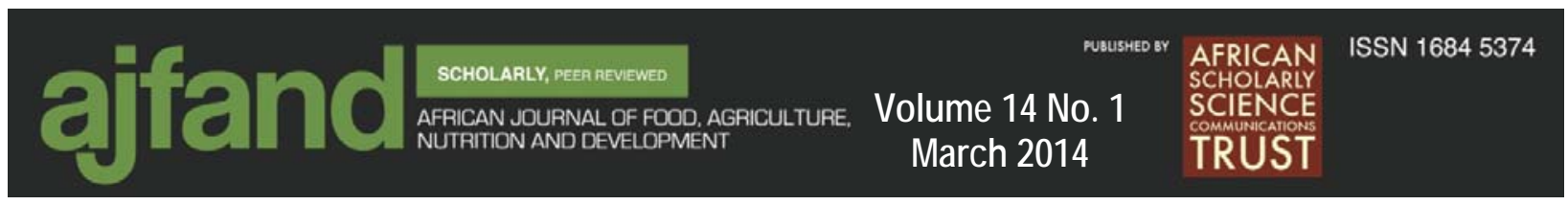

characteristics of farmers; (b) identify the prevalent ill health conditions; (c) estimate the number of farming days lost to ill health by a household; and (d) analyze the effect of ill health on agricultural production in the study area.

\section{LITERATURE REVIEW}

Agriculture is important as a sector that is the bedrock of development and so is the issue of health care for the agricultural population in Nigeria. The production and productivity of the agricultural sector is linked to health status of those involved in the sector [19].

Healthy individuals are expected to possess higher level of human capital and would be more productive than those without good health [20].

In a study of the impact of schistosomiasis and malaria on rice production in Mali by Audibert [13], using a production function model without controlling for illness endogeneity, it was found that while schistosomiasis prevalence reduced output, malaria exhibited no effect on it. A study of technical efficiency in Mali by Audibert and Etard [14] revealed that treatment for schistosomiasis increased technical efficiency. This implies that the prevalence of schistosomiasis would impact negatively on agricultural output. This also holds for other ill health conditions. The impact of health shocks on output can occur through the loss of labour days. In a study to determine the impact of health problems on the family labour used in rice production in Mali, Larochelle and Dalton [15] revealed that a day of illness in an adult agricultural worker resulted in more than a day of labour loss.

Measuring with accuracy the economic effect of transient illness, whether directly or through its impact on agricultural production is extremely complex. One factor that accounts for this complexity is the presence of coping strategies employed to mitigate the impact of ill health. These include timing of labour intensive management practices with periods of low diseases prevalence. Other strategies include substituting capital for labour, intra-family labour substitution as well as substituting machines for human labour [12].

While economic loss of diseases can be underestimated if the secondary effects of coping strategies are not taken into consideration, overestimation of economic loss (loss of output) due to diseases can also occur if these coping strategies are not taken into account. From which ever angle one sees it, the fact remains that there is a cost of illness either directly or indirectly as an opportunity cost. In this study, transient ill health was measured as the number of days of agricultural activities in which the head of a household is indisposed to farming activities due to ill health.

Building on health- labour models, which assumes farm production as a function of land labour, capital, health shocks and a vector of household and environmental characteristics such as $\mathrm{Y}=\mathrm{Y}(\mathrm{L}, \mathrm{F}, \mathrm{K}, \mathrm{H}, \mathrm{Z})$, Larochelle and Dalton [15] measured the impact of health shocks in two dimensions. The first dimension involves the measurement of direct impact which 


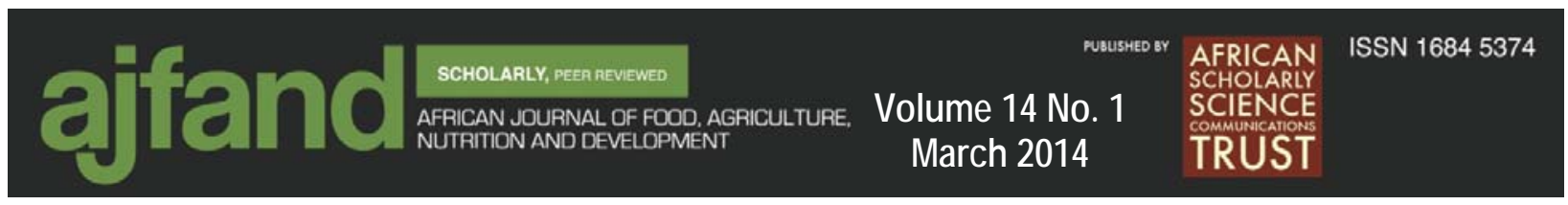

refers to the working days lost to illness affecting family members involved with agricultural production during a farming season. The second dimension involved the indirect impact which concerns illness episodes during a farming season involving a family member not involved with agricultural production- where members of the family who are active in agriculture have to sacrifice farm work to care for their sick. The model adopted in this study, however, combines the two dimensions, taking into account the total number of days lost by a household on account the ailments of those involved with agricultural production and those of other members of the family. Sometimes those involved with farm work may lose time caring for those not involved with farm work. Also, the impact of ill health on labour is assumed to exist and therefore, implied. Thus, the number of days lost to illness by a farmer is expected to have a negative effect on agricultural production.

\section{METHODOLOGY}

Kogi State is located in central Nigeria in West Africa. It was created on the $27^{\text {th }}$ day of August 1991. Kogi is headquartered at Lokoja, a city located on the confluence of the two major rivers in the country- Niger and Benue- and is bordered by the states of Nassawara to the northeast; Benue to the east; Enugu, Anambra, and Edo to the south; Ondo, Ekiti, and Kwara to the west; and Niger to the north. Abuja Federal Capital Territory also borders Kogi to the north.

The state consists of a wooded savanna region bisected by the southward-flowing Niger River; the Benue River, a major tributary of the Niger, forms part of the state's northeastern border. The total land area of the state is $28,313.5 \mathrm{~km}^{2}$ and consists of a wide stretch of arable land for farming, good grazing ground for livestock and large bodies of water for fishing. The Igala people are the main ethnic group and inhabit east of the Niger, while the Ebira and Yoruba live west of the river. Agriculture is the mainstay of the economy and provides employment for about $80 \%$ of the population. Major crops include yams, cassava, rice, sorghum, beans, maize, and cotton. According to the 2006 census figures (which showed that it is the $19^{\text {th }}$ most populous state in a federation of 36 states and a state-like geographical entity called the Federal Capital Territory), the population of the state- which is mostly agrarian- is 3,278,487. Kogi is also the second poorest state in the federation. The state is marked with two distinct seasons: the wet season which spans through middle of April to October and the dry season which spans through November to March. For the purpose of agricultural development, especially in the area of extension delivery system,-it is divided into four agricultural zones. 

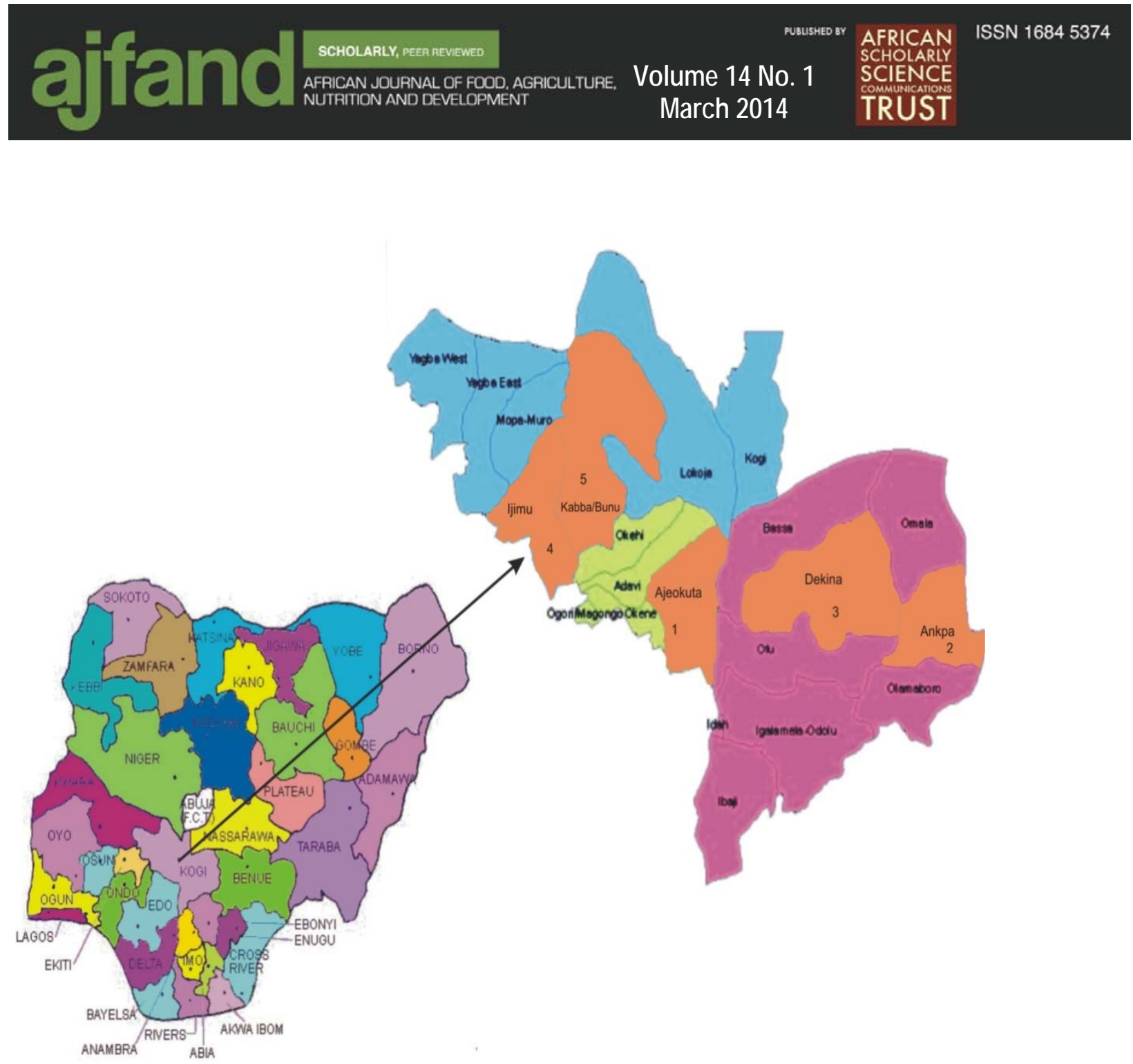

Figure 1: Map of Nigeria showing the study area (enlarged)

The sample was spread over the entire state and the sample frame was obtained from the 4 zonal ADP offices. The use of a multistage random sampling procedure was employed. First, four local government areas were randomly selected from each zone. The second stage involved the selection of 2 farming communities from each of these local governments. Finally, depending on the size of total number of farmers in each community, $25-40$ farm households were randomly selected from each; in all a total of 280 community members were selected for questionnaire administration. Data on the personal characteristics of household heads, households' characteristics, farm outputs (valued in Naira), prevalent disease conditions as well as number of days lost to ill health were generated. Seventeen copies of the questionnaire were, however, either badly completed or not retrieved and, therefore, could not be used for the analyses. Descriptive statistics and production function analyses were used to achieve the sought objectives. 


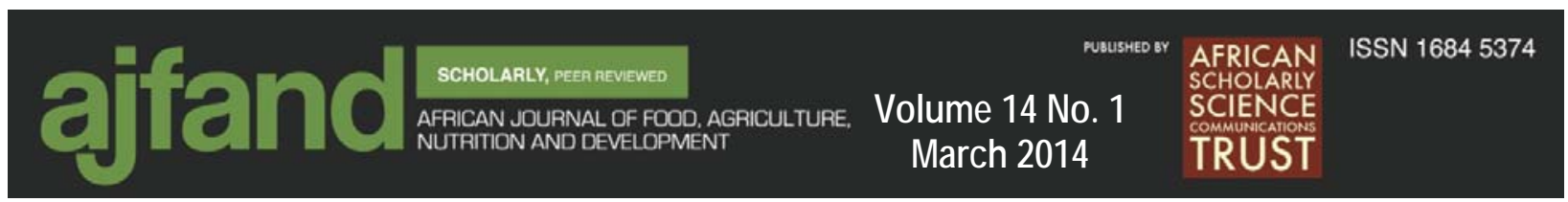

This study focused on the agricultural output from different crop enterprises- and did not set out to measure the wealth of a household. To arrive at a common measure of value of the agricultural commodities for a house hold, the naira value of the various commodities produced by that household was used. The sum of the naira value of all commodities produced by individual households- both consumed and disposed- yields the total naira value of agricultural output for the households.

\section{Model specification}

\section{Explaining the Relationship between Health and Agricultural Production}

The production function is specified as follows:

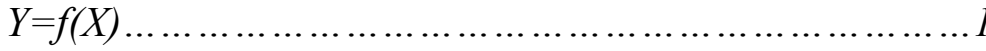

The linear, semi log, double log and reciprocal functional forms were experimented with. Based on theoretical, statistical and econometric considerations, the double log functional form was chosen as the lead equation. It is specified as:

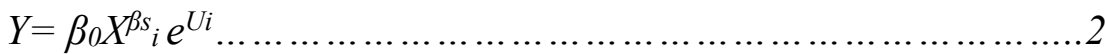

This may be alternatively stated as:

$\ln Y=\ln \beta_{0}+\ln \beta_{1} X_{1}+\ln \beta_{2} X_{2}+\ln \beta_{3} X_{3}+\ln \beta_{4} X_{4}+\ln \beta_{5} X_{5}+\ln \beta_{6} X_{6}+\ln \beta_{7} X_{7}+\ln \beta_{8} X_{8}$ $+\ln \beta \beta_{9} X_{9}+u_{i}$ .3

where $\ln =$ natural $\log$.

For the purpose of estimation, we may, letting $\alpha=\ln \beta 0$, re state equation 3 as:

$\ln Y=\alpha+\ln \beta_{1} X_{1}+\ln \beta_{2} X_{2}+\ln \beta_{3} X_{3}+\ln \beta_{4} X_{4}+\ln \beta_{5} X_{5}+\ln \beta_{6} X_{6}+\ln \beta_{7} X_{7}+\ln \beta_{8} X_{8}+\ln \beta_{9} X_{9}$

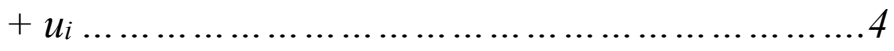

Where:

$\mathrm{Y}=$ Naira value of farm outputs (note: 1 US dollar $=137$ naira at the time of survey)

$\mathrm{X}_{1}=$ Years of schooling,

$\mathrm{X}_{2}=$ Days lost to sickness by household members

$\mathrm{X}_{3}=$ Farm size (ha)

$\mathrm{X}_{4}=$ Family size

$\mathrm{X}_{5}=$ Extension contact (number of extension contacts in the last farming season)

$\mathrm{X}_{6}=$ Labour (in man days)

$\mathrm{X}_{7}=$ Credit accessed (Naira amount of credit accessed in the last farming season)

$\mathrm{X}_{8}=$ Age of household head (years)

$\mathrm{X}_{9}=$ Naira value of chemical used (fertilizer, herbicides etc)

$\mathrm{u}_{\mathrm{i}}=$ error term

$\alpha=$ intercept and the $\beta_{\mathrm{is}}$ represent the coefficients of the explanatory variables 


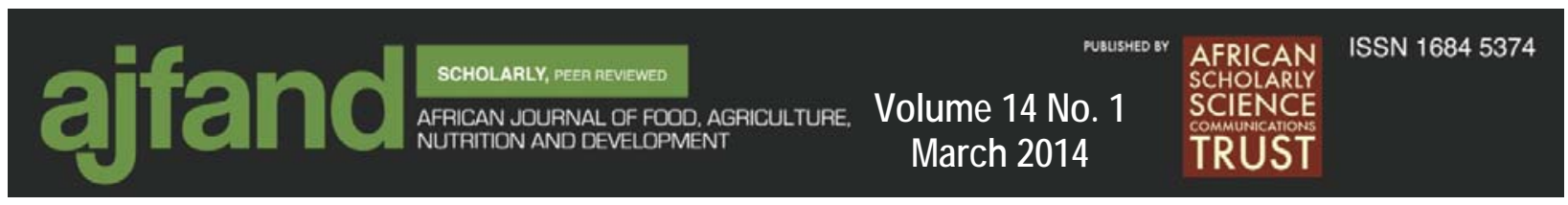

\section{RESULTS}

\section{Socioeconomic characteristics of farm households}

Tables 1 and 2 present the socioeconomic characteristics of farm households in the area. The average age (46.4) is close to the national average age of 47 years. Though this is suggestive of an economically viable population (in fact $76 \%$ of the farmers were below the age of 51), it actually reflects an aging population in that the life expectancy for Nigeria is 47-50 years [17]. Most of the farm households were male-headed.

The average years spent receiving formal education was 7.2. Half of the household heads had primary education at the most. The level of education in the study area was low and this does not come as a surprise as the state is one of the educationally less developed states and the second poorest in the federation. Education has been identified by scholars as an economic imperative which can help farmers become better technical managers of resources. Education also enhances the adoption and application of innovation.

The average family size (6.5) is Close to the national average of 7. Family size has implication for labour and expenditure depending on the dependency ratio. The average farm size (1.43 ha) is slightly higher than the national average of 1.3 . Though the study targeted smallholder farmers, the closeness of the average farm size for the area to the national average is reflective of the fact that most farmers in the country... in the country are smallholder farmers. The naira value of the output per head/month in the last cropping season measured in naira was found to be $\$ 553.8$. This is far less than the national average of $\$ 834.02$ [17] and the average of $\$ 814.24$ found for agricultural workers in the same study area suggesting that in terms of agricultural production, farmers in the area are sinking deeper into poverty [18].

Table 3 presents the ill health related information. It reveals that the most prevalent disease conditions in the area include hygiene and environment related ailments like malaria, typhoid and diarrhea (all constituting 85.9\%) with malaria as the most common.

The number of farming day(s) lost to ill health consisted of the number of day(s) in which a member of a household was sick including days spent receiving treatment and the day(s) spent recovering from the illness in the case of a member involved with farm work, and days in which such a member of the household lost on account of the ill health of another household member. Information in Table 3 reveals that 46.7 percent of the households lost between one and five farming days on account of illness of a member on one extreme, while on the other extreme, $6.7 \%$ of them lost over 20 farming days due to illness of a member. The summary of this variable in Table 2 shows that the least number of days lost to illness was two, the highest number of days lost to illness was 24 and the mean number of days lost to illness was eight. 


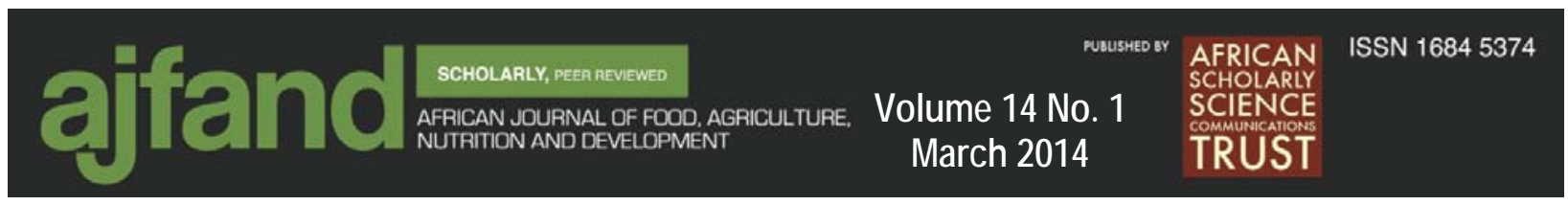

\section{Effect of ill Health on Agricultural Production}

Table 4 shows the effects of various variables on the output of farmers in the study area. The coefficient of determination indicates that $77.3 \%$ of the variation in output was explained by the independent variables. The estimated elasticities of the variables showed that agricultural output increases as years of schooling (0.056), farm size (0.419), family size (0.099), number of contacts with extension agents (0.018), man-days of labour (0.012), amount of credit accessed (0.25) and amount spent on agricultural chemicals (0.06). The coefficients of years of schooling and amounts spent on agricultural chemical were however not significant. The estimated elasticities for the number of days lost to ill health $(-0.09)$ was negatively signed and significant at $5 \%$. That of the age of household head $(-0.248)$ was also negatively signed but insignificant.

\section{DISCUSSION}

Evidence from the regression result reveals that the value of the outputs increases with the farm size of the farmers. Aside from the fact that a large farm size will produce a higher level of output than a smaller one, (all other factors remaining the same) the possibility of nutrient depletion is lower with as larger farm size as the farmers are able to let certain portion fallow. This is however unlikely to be the case for a farmer with smaller holdings who will have to embark on continuous cultivation. Farm size also affects the adoption of innovation. Study by Adejoh, Onuche and Edoka [21] has shown that farmers with larger farm sizes are more likely to adopt agricultural innovations.

Farm output measured in naira was also found to increase with family size. Family size has implications for labour, the larger a family size, the more available labour it has for farm work. The study also found a significant relationship between output and labour as measured in man-days. The quantity of labour is an important determinant of production level in Nigerian agriculture especially in the rural areas where mechanization is completely absent. Amount of credit accessed was also positively linked with farm output. Number of extension contacts also exhibited a significant positive relationship with agricultural output. This contact aims to bring innovation to the farmers and follow them up in the adoption process and agrees with the findings of Adejoh, Onuche and Edoka [21]. Access to credit has been found to be a leverage for agricultural production in some aspect like procurement of inputs, access to / and adoption of innovation as well as expansion of the scale production [20].

The regression result also showed that output decreases with the number of days in which farmers were not available for farming on account of ill health. This agrees in part with the findings of Asenso-Okyere, Chiang, Thangata and Andam[11] that ill health reduces the time available for farm work. Ill health, apart from reducing productivity and the amount of resources available for farm work, to the extent that it causes farmers to lose days of farm operations, reduces the quantity of labour days available to farm operations and 


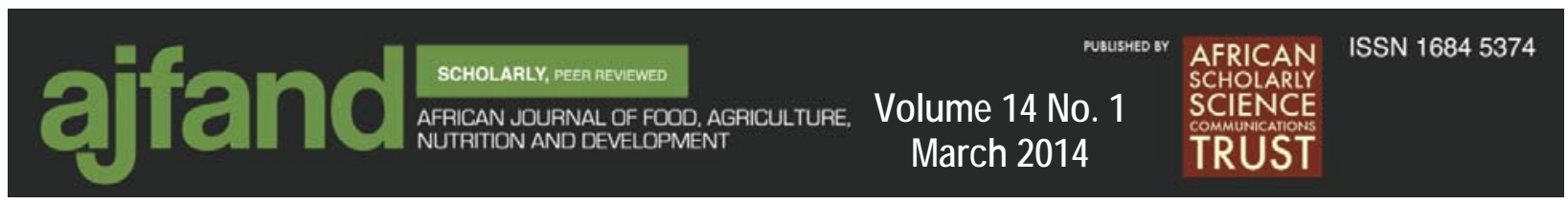

consequently reduces output. The severity of this negative impact of health shocks depends on the timing and season of the illness. The timing of health shocks is important partly because agriculture in the area is weather dependent and also because crop production is time sensitive. Certain crops have to be cultivated at particular periods in a farming season and farming activities like planting, weeding and fertilization, have a great effect on output. A delay in any of these cultural practices will most definitely affect output negatively. For instance delayed weeding will definitely result in low yield.

The study presents the direct picture of the impact of ill health on agricultural production enterprises by taking into account the number of farm days lost to ill health by farming members of a family. It also brings to light the fact that policy intervention should dwell on all the health problems and not a single disease condition.

\section{CONCLUSION}

This study was carried out to identify the prevailing health and agricultural production nexus. Evidence indicates a significant negative relationship between ill health as measured by the number of days lost by member(s) who participated in farm work and agricultural output in Kogi state of Nigeria. The study found that health shocks impact negatively on agricultural production by reducing the number of days available for farm work. Reduction in incidence of these disease conditions can go a long way to improve on agricultural production. It is strongly suggested that intense research attention be focused on environmental and hygiene-linked ill health conditions like the ones mentioned in this study in order to further elicit the nature of their relationships with rural livelihoods.

\section{RECOMMENDATIONS}

Since health status is an important variable in agricultural production, healthcare should be made more accessible to the people in rural Nigeria. By not treating malaria, typhoid and diarrhea, agricultural production in Kogi state suffers and this has implications on food security and rural development. It is, therefore, recommended that government invest more research and development effort into the provision of and accessibility to health care in rural areas in Kogi state. Such efforts should also include the provision of adequate health and environmental education for the rural population as the most common ailments discovered in the study area are actually hygiene and environment related. 


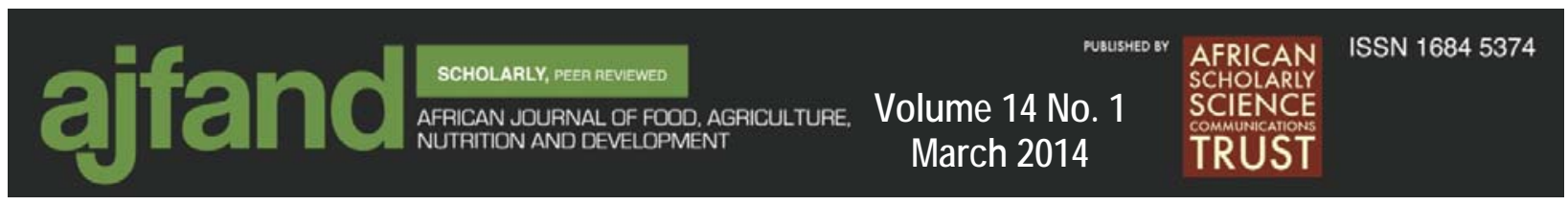

Table 1: Socio Economic Characteristics of Respondents

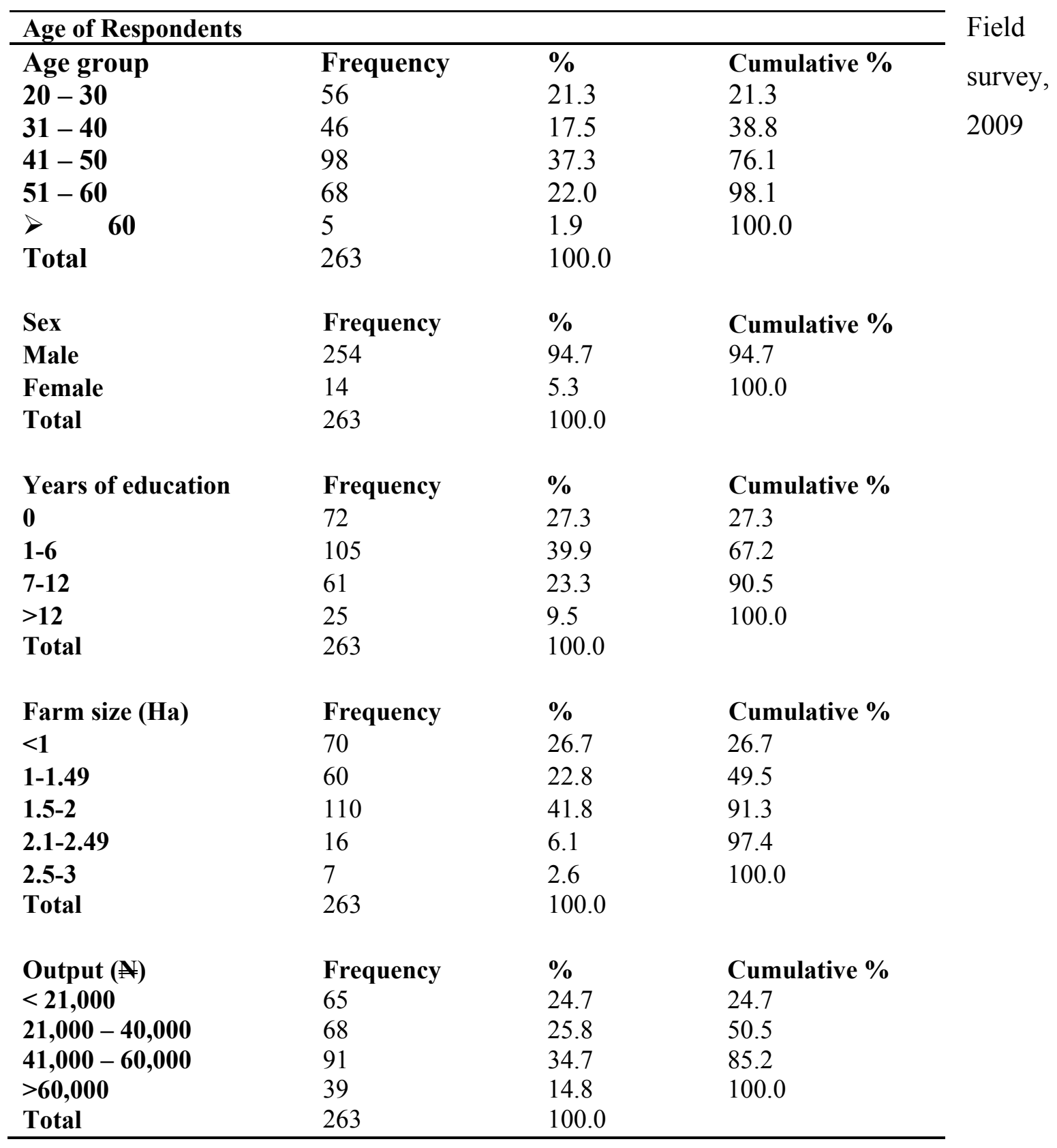




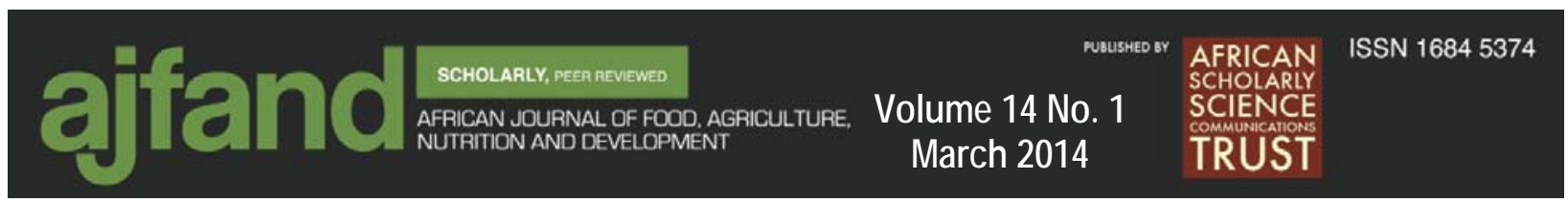

Table 2: Summary of selected variables

\begin{tabular}{|c|c|c|c|c|}
\hline Variable & Mean & $\mathrm{SD}$ & Maximum & Minimum \\
\hline Age & 46.4 & 11.64 & 61 & 22 \\
\hline Years of schooling & 7.42 & 5.82 & 15 & 0 \\
\hline Family size & 6.53 & 3.21 & 17 & 3 \\
\hline Farm size & 1.4 & 0.75 & 3 & 0.5 \\
\hline Days lost to ill health & 8.2 & 6.25 & 24 & 2 \\
\hline $\begin{array}{l}\text { Naira value of } \\
\text { output }\end{array}$ & $41,206.7$ & 19778.51 & 101,000 & 12,000 \\
\hline
\end{tabular}

Field survey, 2009

Table 3: Prevailing Ailments Types and Days lost to health shocks

\begin{tabular}{llll}
\hline Type of ailment & Frequency & $\mathbf{\%}$ & Cumulative\% \\
Malaria & 100 & 38.0 & 38 \\
Typhoid & 86 & 32.7 & 70.7 \\
Diarrhea & 40 & 15.3 & 85.0 \\
Others & 37 & 14.0 & 100.0 \\
Total & 263 & 100.0 & \\
& & & \\
Days lost to illness & & & \\
$\mathbf{1}-\mathbf{5}$ & 70 & 46.7 & 46.7 \\
$\mathbf{6 - 1 0}$ & 42 & 28 & 74.7 \\
$\mathbf{1 1 - 1 5}$ & 28 & 18.6 & 93.3 \\
$>\mathbf{1 5}$ & 10 & 6.7 & 100 \\
Total & 150 & 100.0 & \\
\hline
\end{tabular}

Field survey, 2009 


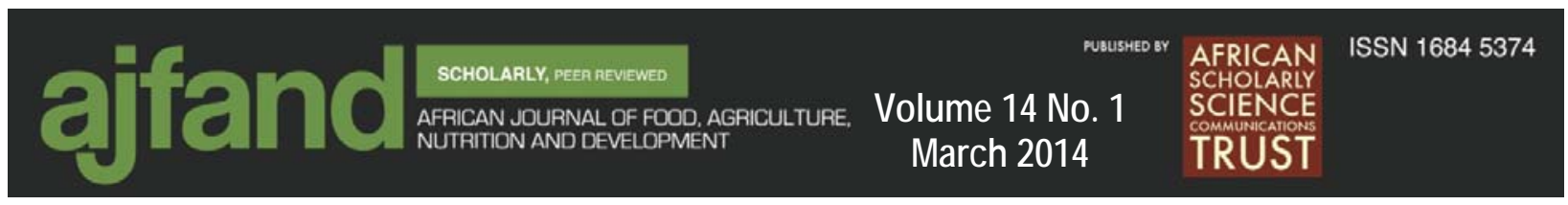

Table 4: Regression Result for Effect of various variables on Agricultural Production

\begin{tabular}{lll}
\hline Variables & Beta & t- value \\
Years of schooling & 0.056 & 1.22 \\
Days lost to sickness & -0.09 & $-2.25^{* *}$ \\
Farm size (Ha) & 0.419 & $5.68^{* * *}$ \\
Family size & 0.099 & $1.67 *$ \\
Chemical used (N) & 0.018 & $2.75^{* * *}$ \\
Labour & 0.012 & $2.01 * *$ \\
Age of household head & -.248 & -1.63 \\
Credit accessed & 0.25 & $3.70^{* * *}$ \\
Extension contact & 0.06 & 1.3 \\
Constant & 6.6 & $18.38^{* * *}$ \\
\hline $\mathrm{R}^{2}=0.773$, Adjusted $\mathrm{R}^{2}=0.760 . *$ sig @10\%, ** sig. @ 5\%, $5 * *$ sig. @ 1\%.
\end{tabular}




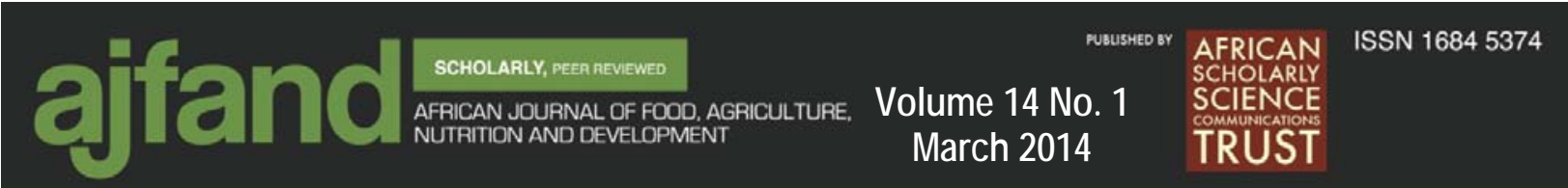

\section{REFERENCES:}

1. Olayemi J K Government Seven Point Agenda: Implication for Agricultural Development. In Ingwa, S. et al eds: Economic and policy series (NAAE). 2008; 1: 215.

2. IFAD. Rural poverty in Nigeria. www.IFAD.org 2007; 1: 1-9. Accessed on $15^{\text {th }}$ June, 2009.

3. Onoja A, Agumagu A C, Ajih L S and G Akor Econometric Analysis of effect of economic policies on food output within $1999-2006$ Proceedings of The $10^{\text {th }}$ Annual National Conference of Nigerian Association of Agricultural Economists held at the university of Abuja, ( $7^{\text {th }}-10$ October). 2008; 1: $143-149$.

4. Falusi A O An Overview of Nigeria Rural Status Problems and potentials. Paper Presented at the National Workshop on Rural Development, NCEMA. 1995: 21-23

5 Savedoff WD and T P Schultz Wealth from Health: Living social investment to Earnings in Europe in Latin America. Soc. Sci. Review.2000; 17: 47-5

6. $\quad$ www.motherland.com. Accessed on $21^{\text {st }}$ December, 2008.

7. NEEDS. National Economic Empowerment and Development Strategy. National Planning Commission, Abuja. 2004; 27-42.

8. Strauss J and D Thomas Health Nutrition and Economic Development J. of Eco. Lit. 1998; 2: 123- 131.

9. Gallup $\mathbf{J} \mathbf{L}$ and $\mathbf{J} \mathbf{D}$ Sachs The Economic Burden of Malaria. Center for International Development at Harvard,1998. P 19.

10. McCarthy FD, Wolf $H$ and $Y$ Wu The Growth costs of Malaria. National Bureau of Economics Research, Working paper 7541: 31 [Online]. Available: www.nberorg/papers/w7541, Accessed December, $10^{\text {th }} 2011$.

11. Asenso-Okyere $\mathbf{K}$, Chiang $\mathbf{C}$, Thangata $\mathbf{P}$ and $\mathbf{K} \mathbf{S}$ Andam Interactions between Health and Farm-Labour Productivity IFPRI food policy reports. 2011.

12. Mock C N, Gloyd S, Adjei S, Acheampong $F$ and $O$ Gish "Economic consequence of injury and resulting family coping strategies in Ghana", Accident Analysis and Prevention. 2003; 35-1: 81-90.

13. Audibert $M$ Agricultural Non-wage Production and Health Status: A Case Study in a Tropical Environment. J. of Dev. Eco. 1986;24(2): 275-9. 


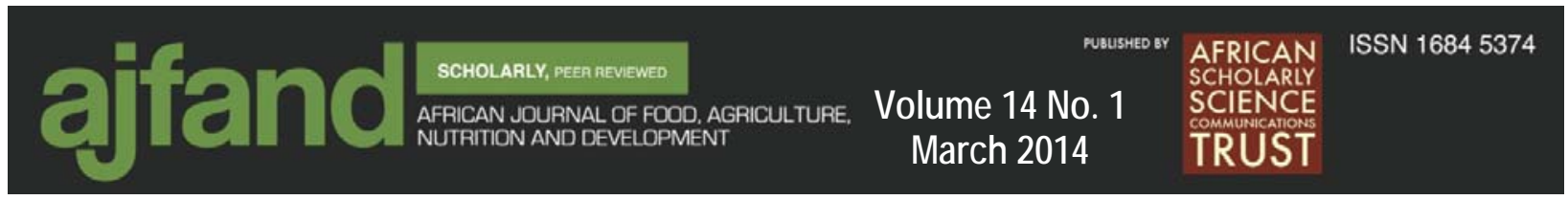

14. Audibert $\mathbf{M}$ and $\mathbf{J}$ F Etard Impact of Schistosomiasis on Rice Output and Farm Inputs in Mali J. of Afr. Econ. 1998; 7 (2):185-207.

15. Larochelle $\mathbf{C}$ and TJ Dalton Contributed paper prepared for presentation at the International Association of Agricultural Economists Conference, Gold Coast Australia August 12-18, 2006 pp 1-24.

16. Onuche U, Adejoh $\mathbf{S} \mathrm{O}$ and $\mathbf{T}$ A Ameh Nonpayment of Health Workers' Salaries and its Impact on Healthcare Delivery in Farming Communities of Kogi State, Nigeria. Aust. j. of basic \& applied Scs. 2011; 5 (11):334-339.

17. National Bureau of Statistics Annual Abstracts of Statistics. National Bureau of statistics Publications, Abuja, Nigeria. 2007.

18. Omonona B T Determinants of Poverty among Agricultural workers in Kogi State. An unpublished $\mathrm{PhD}$ thesis in the Department of Agricultural Economics, University of Ibadan, Nigeria. 2001.

19. Ajanla $\mathbf{O}$ A, Sani $L$ and $S$ A Adeyinka "Accessibility to Health care Facilities: Panacea for Sustainable Rural Development in Osun state, Southwestern Nigeria”. $J$. of Human Ecology. 2005; 2: 26-41.

20. Alves LF, Andrade $M$ V and $\mathbf{P}$ B R Macedo Health and Lasonment in Brazil Memograph, 2002: 273-287.

21. Adejoh S O, Onuche $\mathbf{U}$ and $\mathrm{M}$ H Edoka Evaluating the Factors influencing the Adoption of Selected Soil management Technologies by Yam Farmers in Olamaboro Local Government area of Kogi State, North central Nigeria. Int. j. of agric econ., Magt. \& Dev. 2010;1 (1):1-10. 